\title{
Orhun Yazıtlarındaki atasözü ve deyimlerin günümüzdeki karşılıklarına yönelik inceleme
}

\section{Mehmet Fatih ÖZCAN1}

\begin{abstract}
APA: Özcan, M. F. (2019). Orhun Yazıtlarındaki atasözü ve deyimlerin günümüzdeki karşllılarına yönelik inceleme. RumeliDE Dil ve Edebiyat Araştırmaları Dergisi, (16), 98-105. DOI: 10.2900o/rumelide.616897
\end{abstract}

\section{Özet}

Dil, bir milletin en önemli sosyolojik varlığıdır. Toplumların ortak tarih ve kültür gibi manevi unsurlarının yanında, toprak birliği ve konuşulan ortak dil gibi maddi unsurları da göze çarpar. Bu unsurlar içinde en önemlilerinden biri de dil ve kültür birliğidir. İşte bu dil ve kültür birliğinin de en önemli aynası şüphesiz atasözleri ve deyimlerdir. Deyimler ve atasözleri, bir milletin dünyaya bakışını ve millî kimliğini yansıtır. Söz varlığımızda ve kültürümüzde önemli yeri olan deyim ve atasözleri, kalıplaşmış özlü sözlerdir. Geçmişten günümüze kadar toplumun ortak duygu ve düşüncelerini yansıtmaktadır. Dilimize zenginlik katan önemli unsurlardır. Bu araştırmada, 8 . yüzyılda dikilen Orhun Yazıtlarındaki deyim ve atasözleri tespit edilmeye çalışılmıştır. Tespit edilen deyim ve atasözlerinin Türkiye Türkçesindeki karşılıkları belirlenmiştir. Bu araştırmada Muharrem Ergin'in "Orhun Abideleri” adlı kitabındaki metinlerden yola çıkılmıştır. Metinlerden tespit edilen deyim ve atasözlerinin Türkiye Türkçesindeki karşılıkları ve anlamları için "Türk Dil Kurumu Atasözleri ve Deyimler Sözlüğü”nden yararlanılmıştır.

Anahtar kelimeler: Orhun Yazıtları, atasözleri, deyimler.

\section{An analysis on the present equivalents of the proverbs and idioms in Orkhon Inscriptions}

\begin{abstract}
Language is the most important sociological entity of a nation. In addition to moral elements such as common history and culture of societies, material elements such as territorial unity and spoken common language are also noticeable. One of the most important of these elements is the language and cultural unity. The most important mirror of this language and cultural unity is undoubtedly the proverbs and idioms. Idioms and proverbs reflect a nation's view of the world and its national identity. The idioms and proverbs that have an important place in our vocabulary and culture are stereotyped wise sayings. They reflect the common feelings and thoughts of the society from the past to the present. They are important elements that enrich our language. In this study, it was aimed to determine the proverbs and idioms in Orkhon Inscriptions written in $8^{\text {th }}$ century, and the present equivalents of the determined proverbs and idioms were identified. The texts in his book "Orhun Abideleri” by Muharrem Ergin were used for this study. "Turkish Language Society Dictionary of Proverbs and Idioms" was used for the meanings and equivalents of the proverbs and idioms identified in the texts.
\end{abstract}

$1 \quad$ Dr. Ö̆gr. Üyesi, Ağrı İbrahim Çeçen Üniversitesi, Eğitim Fakültesi, Türkçe ve Sosyal Bilimler Bölümü, Türkçe Eğitimi ABD (Ağrı / Türkiye), mefo3@hotmail.com, ORCID ID: 00oo-0002-0721-9422 [Makale kayıt tarihi: 26.05.2019-kabul tarihi:16.09.2019; DOI: 10.29000/rumelide.616897] 
Keywords: Orkhun Inscriptions, proverbs, idioms.

\section{Giriş}

Atasözleri, halk arasında geçmişten günümüze kadar söylenegelen, genellikle öğüt veren özlü sözlerdir. Atasözleri uzun gözlem ve tecrübeler sonucu oluşmuştur. Kalıplaşmış sözlerdir. Söyleyeni belli değildir. Dolayısıyla toplumun ortak ürünüdür. Geleneksel yaşamdan izler taşır. Aksan, atasözlerini "çoğunlukla bir cümle biçiminde oluşarak bir yargı anlatan, kimi zaman ölçü ve uyakla, söyleyiş açısından daha etkili olmaya yönelen sözlerdir” tanımını yapar (Aksan, 2009, s. 38). Soykut (1974, s. 34)'a göre de atasözü, yüzyıllar boyunca yaşanmış veya rastlanmış, müşahede edilmiş sayısız ve birbirinden farklı olayları değerlendiren, onları ayrı ayrı klişeler hâline getirerek sınıflandıran, nihayet dedelerden torunlarına intikal eden özlü sözdür. Diğer bir tanımlamada ise atasözünün çoğu kez mecaz anlamlı ve kelimeleri değiştirilemeyen sözler olduğu; toplum tecrübesinin, zekâsının, idrakinin veciz numuneleri olduğu, atalar sözü veya darb-ı mesel olduğu söylenmiştir (Şahin, 2013, s. 206). Atalar sözü, bir bakıma molozu atılmış, komprime, süzme sözlerdir; bu sözlerde göze çarpan edebî sanatlar, hafızalarda yaşamalarını ve tesir kudretlerini artıran tamamlayıcı unsurlardır (Elçin, 2004, s. 628). Atasözleri az sözle çok şey anlatan böylece barındırdıkları söz ve anlam sanatları bakımından dilin en çarpıcı kullanımlarındandır (Ulucan, 2005, s. 50). Anlam yönünden kesin ve açıklık bulunan atasözleri aynı zamanda anlam zenginliğine de sahip kesin yargı bildiren öğüt verici söz gruplarıdır (Hatipoğlu, 1964, s. 468). Dilçin (2000, s. XV)'e göre ise atasözü, beşer cemiyetiyle beraber doğmuş, onunla birlikte oba, boy ve oymak olarak asırlarca göçebe hayatı yaşamış ve nihayet gelişip özleşerek de ulusal hâle yükselmiş, medenîleşmiş törelerdir tanımlarına rastlanmıştır. Edebi sanatların kullanılması sözün etkisini ve kalıcılığını arttırmak için başvurulan bir yöntemdir. Atasözlerinin tazeliğini yüzyıllar geçse bile korumasında çeşitli anlatı yollarının, söz ve anlam sanatlarının etkisi fazladır. Bunu Türkçenin en eski metinleri olan Orhun yazıtlarında (Akçay ve Şahin, 2015, s. 55) ve Divan-ı Lügat-it Türk’te de varlı̆̆ına işaret edilmektedir (Zülfikar, 1988, s. 322).

Eski çağlardan beri "istılah" ve "tâbir" adlarıyla da kullanılmış olan deyimler kısa ve özlü anlatım şekilleridir (Erenoğlu, 2007, s. 1151). Deyim asıl anlamlarından uzaklaşarak yeni kavramlar meydana getiren kalıplaşmış sözler veya söz öbekleri; iki veya daha çok kelimeden kurulu bir çeşit dil ifadesi olan, isim, sıfat, belirteç, yalın ve birleşik eylem görünüşlü olan dilsel yapılar (Elçin, 2004, s. 642). Aksan (2009, s. 35) deyimi, belli bir kavramı, belli bir duyguyu ya da durumu dile getirmek için birden çok sözcügün bir arada, seyrek olarak da tek bir sözcüğün yan anlamında kullanılmasıyla oluşan sözler olarak tanımlar.

Atasözleri (Savlar, Proverbes) ve deyimler (Tabirler, İdiotismes) atalardan kalmış olan kelime gruplarıdır. Atasözü ve deyimler temel olarak geçmişte yaşanılanlardan hareketle halkın ortak ürünü olarak günümüze ulaşmıştır. Zülfikar (1988, s. 322)'ın da belirttiği gibi atasözü ve deyimler ile ilgili ilk örnekler Orhun Yazıtlarında yer almıştır.

Orhun Yazıtlarından; Köl Tigin yazıtı, Köl Tigin'in ağabeyi ve Köktürklerin kağanı Bilge Kağan tarafından, 732 yılında, kardeşi adına, kardeşinin hizmetlerinden dolayı ona duyduğu minneti göstermek amacıyla, dikilmiştir (Ergin, 2012, s. XVII). Bilge Kağan, Türk milleti için olduğu kadar kendisi için de çok büyük bir mana ve değer ifade eden kahraman kardeşi Köl Tigin'in ölümü üzerine, gözünden yaşlar dökmek, haykırıp feryat etmek istemekte fakat temsil ettiği yer dolayısıyla bunu abideleştirerek dile getirmektedir (Ercilasun, 2004, s. 134). Türk adının, Türk milletinin isminin geçtiği ilk Türkçe metin, ilk Türk tarihi, Türk devlet adamlarının millete hesap vermesi, milletle hesaplaşması, 
Türk nizamının, Türk töresinin, Türk medeniyetinin, yüksek Türk kültürünün büyük vesikası. Türk yazı dilinin ilk, fakat harikulade işlek örneği. Türk yazı dilinin başlangıcını milâdın ilk asırlarına çıartan delil. Türk ordusunun kuruluşunu en az 1250 sene öteye götüren vesika. Türklüğün en büyük iftihar vesilesi olan eser. İnsanlık âleminin sosyal muhteva bakımından en manalı mezar taşları. Dünyanın bugün belki de en büyük meselesi olan Çin hakkında 1250 sene evvelki Türk ikazı. vs. vs. (Ergin, 2015, s. 15).

Batur ve Yıldırım (2013, s. 314)'a göre Orhun Yazıtları, Türk dilinin en eski yazılı kaynaklarından biri olup VIII. yüzyılda dikilmiş Bengü taşlardır. Bilge Kağan, Költigin ve Vezir Tonyukuk ağzından Türk milletinin o dönemde öteki millet ve kavimlerle yaptıkları savaşların, mücadelelerin anlatıldığı, Türk milletinin bekası için birtakım uyarılar içeren, Türk askeri geleneği, hükümdarlık anlayışı, devlet düzeni, Türk tarihi, kültür ve geleneği hakkında çeşitli bilgilere ulaşmamızı sağlayan Orhun Yazıtları hitabet niteliğinde yazılmış metinlerdir. Bu tanımlardan Orhun Yazıtlarının, Türk yazı dilinin ilk örneklerini ortaya koyduğunu, dönemin tarihi, siyasi ve yaşayışılla ilgili bilgileri Türkçe'nin gücü ve köklü geçmişiyle aktardığını söyleyebiliriz.

Orhun yazıtlarının gerek yazılış amaçları ve konuları gerekse kısa oluşları atasözlerine başka tür ve metinlerde olduğu kadar rastlamamıza olanak vermemektedir (Aksan, 200o, s. 96). Buna rağmen, yazıtlarda tespit edilen atasözleri, Türk toplum hayatının her devresinde sık sık kullandığı, öz mesajlar ve değer yargıları olması yönüyle dikkate değerdir (Şenocak, 2001, s. 174).

\section{Amaç}

Bu araştırma ile Türk dilinin ilk yazılı kaynağı olan Orhun Yazıtlarındaki deyim ve atasözlerinin tespit edilmesi ve Türkiye Türkçesindeki karşılıklarının veya benzerlerinin bulunması amaçlanmıştır.

\section{Yöntem}

Çalışmamızda, Muharrem Ergin tarafından kaleme alınan "Orhun Abideleri” adlı eser esas alınmıştır. $\mathrm{Bu}$ çalışmada nitel araştırma yöntemlerinden "doküman incelemesi” yöntemi kullanılmıştır.

Doküman incelemesi, araştırılması hedeflenen olgu veya olgular hakkında bilgi içeren yazılı materyallerin analizini kapsar. Doküman incelenmesi, hemen her araştırma için kaçınılmaz olan bir veri toplama tekniğidir. Belge yoksa tarih de yoktur (Madge,1965, s. 75 ).

Bilgi toplama yöntemi olarak kullanılan doküman inceleme yöntemi Foster'ın belirttiği; (1) dokümanlara ulaşma, (2) orijinalliği kontrol etme, (3) dokümanları anlama, (4) verileri analiz etme ve (5) veriyi kullanma şeklinde yapılmıştır (akt. Yıldırım ve Şimşek, 2008, s. 193).

\section{Orhun yazıtlarındaki atasözü ve deyimlerin Türkiye Türkçesindeki benzerleri}

\subsection{Orhun yazıtlarındaki atasözlerinin Türkiye Türkçesindeki Benzer atasözü karşılıkları}

\begin{tabular}{|c|}
\hline \multicolumn{1}{|c|}{ Metin: } \\
\hline Türk budun tokurkak sen. Açsık tosık ömez sen. Bir todsar açsık ömez sen (Ergin, 2015, s. 36). \\
\hline$\underline{\text { Türkiye Türkcesine Aktarma: }}$ \\
\hline Türk milleti, tokluğun kıymetini bilmezsin. Açlı, tokluk düşünmezsin. Bir doysan açlığı düşünmezsin (Ergin, \\
2015, s. 37).
\end{tabular}




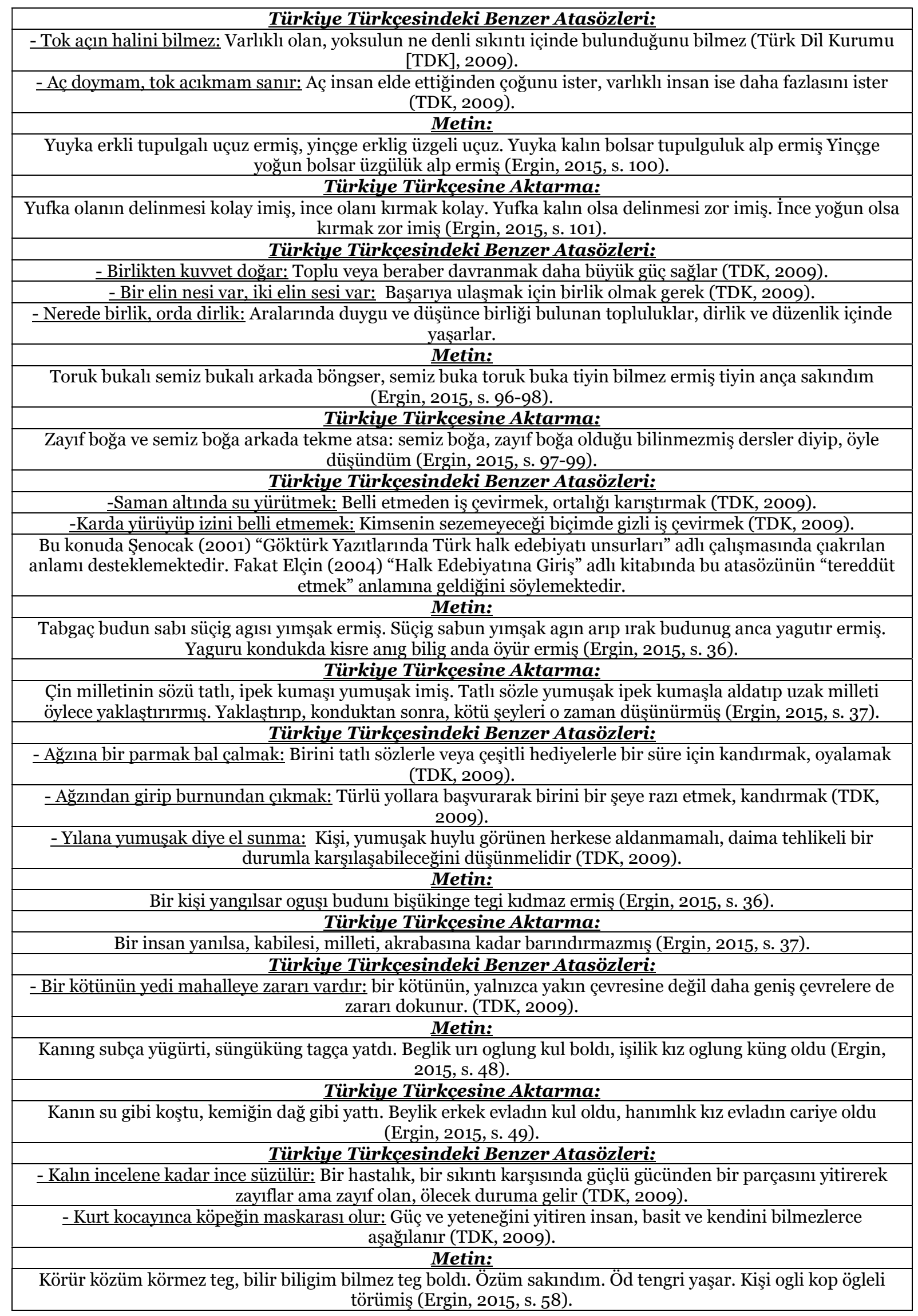




\begin{tabular}{|c|}
\hline$\underline{\text { Türkiye Türkçesine Aktarma: }}$ \\
\hline $\begin{array}{c}\text { Görür gözüm görmez gibi, bilir aklım bilmez gibi oldu. Kendim düşünceye daldım. Zamanı Tanrı yaşar. } \\
\text { İnsanoğlu hep ölmek için türemiş (Ergin, 2015, s. 59). }\end{array}$ \\
\hline$\underline{\text { Türkiye Türkçesindeki Benzer Atasözleri: }}$ \\
\hline - Ölümden öte köy yoktur: Her insan bir gün öleceğini bilmeli, sonu gelmez istekler peşinde koşmamalı, \\
\hline davranışlarını, işlerini bu bilinçle düzene koymalıdır (TDK, 2009). \\
\hline
\end{tabular}

\subsection{Orhun abidelerindeki deyimlerin Türkiye Türkçesindeki benzer deyimlerin karşılıkları}

\begin{tabular}{|c|}
\hline Metin: \\
\hline Birigerü Tokuz Ersinke tegi süledim (Ergin, 2015, s. 34). \\
\hline Türkiye Türkcesine Aktarma: \\
\hline Güneyde Dokuz Ersine kadar ordu sevk ettim (Ergin, 2015, s. 35). \\
\hline Türkiye Türkçesindeki Benzer Deyimler: \\
\hline - süledim: sevk etmek, yollara dökülmek \\
\hline Metin: \\
\hline [Bunç]a budun kop itdim (Ergin, 2015, s. 34). \\
\hline Türkiye Türkçesine Aktarma: \\
\hline Bunca milleti düzene soktum (Ergin, 2015, s. 35). \\
\hline Türkiye Türkcesindeki Benzer Deyimler: \\
\hline $\begin{array}{c}\text { - it: düzene sokmak, ahenk vermek, çekiye gelmek, düzen vermek, düzene koymak, hale yola koymak, yoluna } \\
\text { koymak }\end{array}$ \\
\hline Metin: \\
\hline Kon anda alkıntıg, arıltıg (Ergin, 2015, s. 38). \\
\hline Türkiye Türkcesine Aktarma: \\
\hline Hep orada mahvoldum, yok edildim (Ergin, 2015, s. 39). \\
\hline Türkiye Türkcesindeki Benzer Deyimler: \\
\hline - arıl-: ortadan kaldırmak, yok olmak, harap olmak, hali harap olmak \\
\hline Metin: \\
\hline Sü sülepen tört bulungdakı budunug kop almış, kop baz kılmıș (Ergin, 2015, s. 40). \\
\hline Türkiye Türkcesine Aktarma: \\
\hline Ordu sevk ederek dört taraftaki milleti hep almıs, hep tabi kılmıs (Ergin, 2015, s. 41). \\
\hline Türkiye Türkcesindeki Benzer Deyimler: \\
\hline - Baz kılmak: boyun eğmek, tabi kılmak \\
\hline Metin: \\
\hline Bașlııı yükündürmiș, tizligig sökürmiș (Ergin, 2015, s. 40). \\
\hline Türkiye Türkçesine Aktarma: \\
\hline Başlya bas eğdirmis, dizliye diz cöktürmüs (Ergin, 2015, s. 41). \\
\hline Türkiye Türkcesindeki Benzer Deyimler: \\
\hline - Bașlıgıg yükündürmiș: baş eğmek, boyun vermek \\
\hline - Tizligig sökürmiș: boyun eğmek, diz çökmek, kazaya rıza göstemek, amana gelmek, kul olmak, dize gelmek \\
\hline Metin: \\
\hline $\begin{array}{c}\text { Yogçı sıgıtçı öngre kün togsıkda Bökli çö[l]üg il Tabgaç Tüpüt Apar Purum Kırkız Üç Kurıkan Otuz Tatar Kıtan } \\
\text { Tatabı bunca budun kelipen sıgramış yoglamıș (Ergin, 2015, s. 40). }\end{array}$ \\
\hline Türkiye Türkcesine Aktarma: \\
\hline $\begin{array}{l}\text { Yasçı, ağlayıvıi doğuda gün doğusundan Bökli Çöllü halk, Çin Tibet, Avar, Bizans, Kırgız, Üç Kurıkan, Otuz } \\
\text { Tatar, Kitav, Tatbı, buna millet gelip ağlamıs, vas tutmus (Ergin, 2015, s. 41). }\end{array}$ \\
\hline Türkiye Türkçesindeki Benzer Deyimler: \\
\hline - Yoglamıș: yasa bürünmek, matem tutmak, yas tutmak, yas çekmek \\
\hline Metin: \\
\hline Türk budun illedük ilin ıçgınu ıdmış (Ergin, 2015, s. 42). \\
\hline Türkiye Türkcesine Aktarma: \\
\hline Türk milleti il yaptığı ilini elden çkarmıs (Ergin, 2015, s. 43). \\
\hline Türkiye Türkcesindeki Benzer Deyimler: \\
\hline - Içgın- : elden çıkarmak, elden gitmek, yoksun kalmak, boş koymak, yoksun bırakr \\
\hline Metin: \\
\hline Tabgaç budunka beglik urı oglın kul boldı (Ergin, 2015, s. 42). \\
\hline kiye Türkcesine Aktarma: \\
\hline
\end{tabular}




\begin{tabular}{|c|}
\hline Çin milletine betlik erkek evladı kul oldu (Ergin, 2015, s. 43). \\
\hline Türkiye Türkcesindeki Benzer Deyimler: \\
\hline - Kul boldı: boyun eğmek, kula kul olmak \\
\hline
\end{tabular}

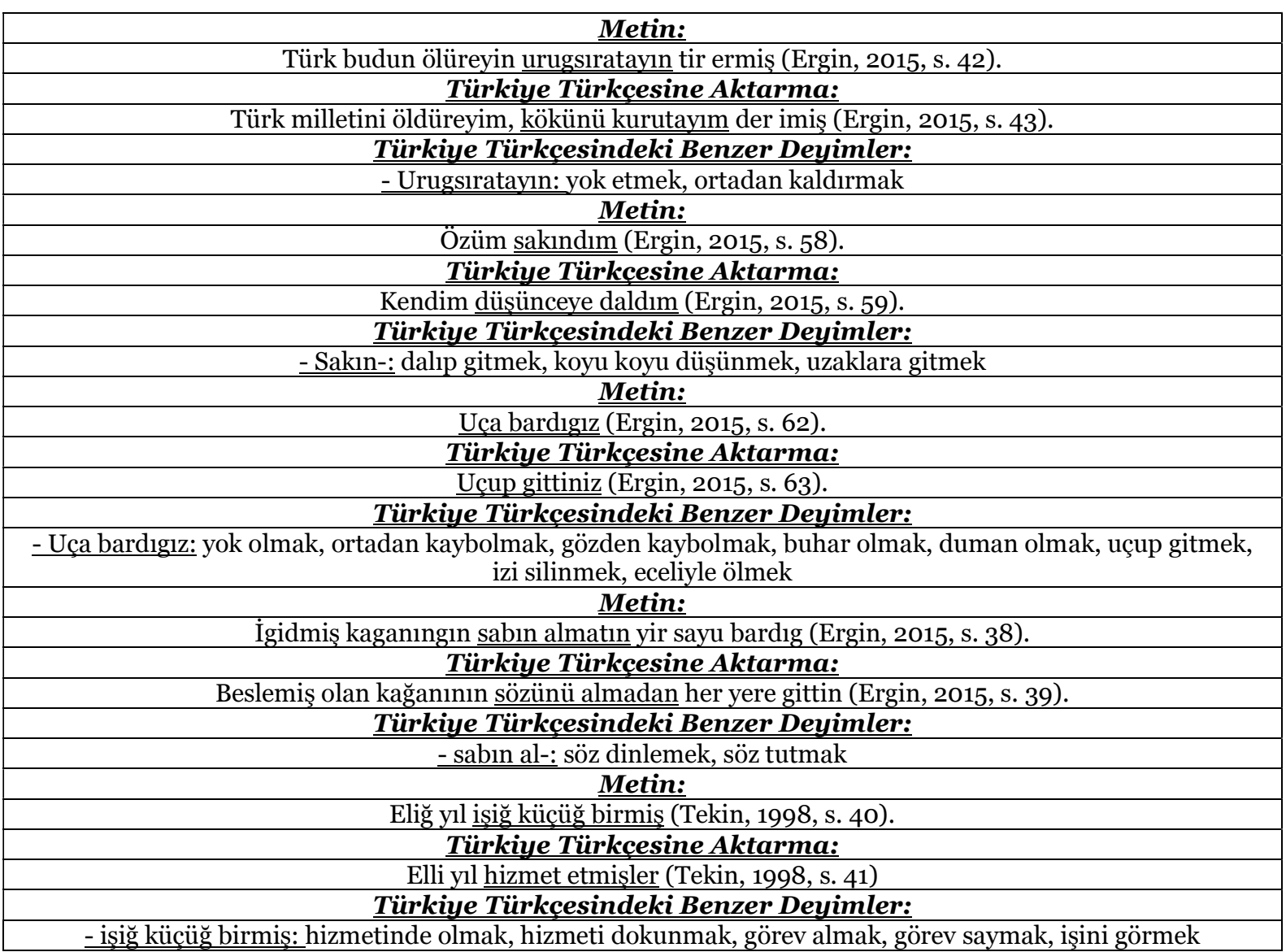

\section{Sonuç ve değerlendirme}

Orhun Yazıtları, söz ve sözcük varlığı olarak zengin bir kaynaktır. Kitabelerde kullanılan deyim ve atasözlerinin anlatımı zenginleştirmesi ve derinleştirmesi ile beraber dönemin toplumsal, siyasi ve milli duruşu üzerinde önemli bir etkiye sahip olduğu görülmüştür.

Çalışmamızın amacı Orhun Yazıtları'nda geçen deyim ve atasözlerini tespit etmek ve Türkiye Türkçesindeki karşllıklarını bulmaktı. Bu çalışmada Muharrem ERGiN’in Orhun Abideleri ve Talat TEKIN’in Orhon Yazıtları kitabından ve Türk Dil Kurumunun “Atasözleri ve Deyimler Sözlüğü”nden yararlanılmıştır. Bazı deyim ve atasözlerinin günümüz Türkçesine aktarılmasında veya benzerliklerinin bulunmasında yukarıda bahsedilen kitaplardan kitabelerdeki deyim ve atasözleri belirlenmiştir. Bu çerçevede ele alınan ifadeler "Türkiye Türkçesindeki Karşllıları" ve "Türkiye Türkçesindeki Benzer Deyim/Atasözleri” şeklinde sınıflandırılmıştır.

Kitabelerde yedi atasözü tespit edilmiştir. Kullanılan atasözleri, dönemin özelliklerine ve yaşanılan olaylara uygun olarak farklı anlamlar taşımaktadır. Kitabelerdeki atasözlerinin temelinde, öğüt verme amacı güdülmüsstür. Bu atasözlerinde empati yapmamak, birlik olmak, hile yapmak, kandırmak, kendine ve başkalarına zarar vermek, zayıf duruma düşmek, sabırlı olmak ve dayanmak konuları işlenmiştir. Kitabelerdeki atasözlerinden ve konularından hareketle Türkiye Türkçesindeki atasözleri 
karşılaştırılmıştır. Sonuç olarak kitabelerdeki atasözleri ile Türkiye Türkçesindeki atasözlerinin aynı anlam kapsamında, farklı şekillerde dile getirildiği sonucuna varılmıştır.

Kitabelerde atasözlerinin yanı sıra on dört deyim tespit edilmiştir. Bazı deyimler metin içerisinde birden fazla kullanılmıştır Kitabede sevk etmek" deyimi 57, "düzene sokmak" deyimi 14, "yok etmek/olmak" deyimi 29, "tabi olmak/kllmak" deyimi 10, "baş eğdirmek" deyimi 10, "diz çöktürmek" deyimi 7, "tas tutmak" deyimi 1, "elden çıkarmak" 2, "kul olmak" 7, "kökünü kurutmak"deyimi 2, "düşünceye dalmak" deyimi 6, "uçup gitmek" deyimi 6, "söz almak” deyimi 6, "hizmet etmek” deyimi 9 kez kullanılmıştır. Bu deyimlerde; ulaşmak, düzen vermek, ortadan kaldırmak, yok olmak, boyun eğmek, üzüntülü olmak, yitirmek, derin düşünmek, söz tutmak ve görev almak konuları işlenmiştir. İşlenen konulara bakıldığında, deyimlerin genel olarak olumsuz durumları dile getirmek için kullanıldığını söyleyebiliriz. Kitabelerdeki deyimlerin anlamından hareketle Türkiye Türkçesindeki deyimlerle karşılaştırılmıştır. Sonuç olarak kitabelerdeki deyimlerin, Türkiye Türkçesinde kullanılan deyimlerle hem anlam hem de yazılış olarak benzer özellikler gösterdiği belirlenmiştir.

Yapılan çalışma sonucunda Orhun Abidelerindeki atasözü ve deyimlerin dönemin söz varlığında önemli bir etkiye sahip olduğu ve Türkiye Türkçesinde birden fazla söz ve sözcük grubunu karşlladığı belirlenmiştir. Asırlar öncesine ait bu metinlerdeki ürünler günümüzde de aynı anlam zenginliğini sürdürmektedir. Bundan dolayı atasözü ve deyimlerin söz varlığımızdaki yeri ve öneminin geçmişten günümüze kadar devam ettiğini söyleyebiliriz.

\section{Kaynakça}

Aksan, D. (2000). En eski Türkçenin izlerinde \& Orhun Ve Yenisey Yazıtları üzerinde sözcükbilim, anlambilim ve biçembilim incelemelerinin aydınlattığı gerçekler. İstanbul: Bilgi.

Aksan, D. (2009). Her Yönüyle Dil-Ana Çizgileriyle Dilbilim(Cilt III). (5. Baskı). Ankara: Türk Dil Kurumu.

Akçay, A. Şahin, N. ( 2015). Türk Dilinin Eski Yazllı Örneklerinin Ortaokul Türkçe Ders Kitaplarında Metin Olarak Yer Alabilirliğinin İncelenmesi Uluslararası Eğitim, Bilim ve Teknoloji Dergisi International Journal of Education, Science and Technology 2015, Cilt 1, Sayı 1, 53-64 2015, Volume 1, Issue 1, 53-6.

Atasözleri ve Deyimler Sözlüğü. (2009). Türk Dil Kurumu. Erişim adresi: http://www.tdk.gov.tr/index.php?option=com_atasozleri\&view=atasozleri.

Batur, Z. ve Ylldırım, G. (2013). Orhun Yazıtlarında anlama ve anlatma becerileri. International Periodical For The Languages, Literature and History of Turkish or Turkic. 8(4), s. 313-333.

Dilçin. D. (2000). Edebiyatımızda Atasözleri, İstanbul : TDK.

Elçin, Ş. (2004). Halk Edebiyatına Giriş. Ankara: Akçă̆.

Ercilasun, A. B. (2004). Baslangıçtan Yirminci Yüzyıla Kadar Türk Dili Tarihi, Akçă̆.

Erenoğlu, D. (2007). “Güvâhî’den Günümüze Atasözleri Ve Deyimler” Turkish Studies International Periodical For the Languages, Literature and History of Turkish or Turkic Volume 2/4 Fall.

Ergin, M. (2012). Orhun Abideleri. İstanbul: Boğaziçi.

Ergin, M. (2015). Orhun Abideleri. İstanbul: Boğaziçi.

Hatipoğlu, V. (1964). “Atasözleri ve Deyimler”. Türk Dili, XIII/152. Mayıs 1964, s.468.

Madge, J. (1965). The Tools of Science An Analytical Description of Social Scince Techniques. Anchor Books Doubleday and Comp.

Onan, B. (2011). Türk Atasözlerinde Dil Farkındalığı ve İşlevsel Dil Kullanımı. Milli Folklor, S. 91. 
Soykut, H. (1974). Türk Atalar Sözü Hazinesi. İstanbul: Ülker .

Şahin, A., (2013). Öğretmenlik Alan Bilgisi, Türkçe. Ankara: Alan Bilgisi.

Şenocak, E. (2001). Göktürk Yazıtlarında Türk halk edebiyatı unsurları. Frrat Üniversitesi Sosyal Bilimler Dergisi. 11(2), s. 165-176.

Tekin, T. (1998). Orhon Yazitları. İstanbul: Simurg.

Ulucan. M. (2005). “Muvakkitzade Mehmed Pertev'in Divanında Atasözleri ve Deyimlerin Kullanımı”. İlahiyat Fakültesi Dergisi, Elazığ: Fırat Üniversitesi Yayınları, Sayı 10, s. 49-80.

Ylldırım, A. ve Şimşek, H. (2008). Nitel araştırma yöntemleri. Ankara: Seçkin.

Zülfikar, H. (1988). Ata Sözü Terimi, Kaynağı ve İmlâsı, Türk Dili LV/438. Haziran 1988, s.322. 